INFLAMMATORY BOWEL DisEASES"

Official Journal of the Crohn's \& Colitis Foundation of America, Inc.

\title{
Infliximab restores the dysfunctional matrix remodeling protein and growth factor gene expression in patients with inflammatory bowel disease
}

\begin{tabular}{|c|c|}
\hline Journal: & Inflammatory Bowel Diseases \\
\hline Manuscript ID: & IBD-12-0863.R1 \\
\hline Wiley - Manuscript type: & Original Research Articles - Basic Science \\
\hline Date Submitted by the Author: & $\mathrm{n} / \mathrm{a}$ \\
\hline Complete List of Authors: & $\begin{array}{l}\text { de Bruyn, Magali; KULeuven, Department of Clinical and Experimental } \\
\text { Medicine; KULeuven, Department Microbiology \& Immunology } \\
\text { Machiels, Kathleen; KULeuven, Department of Clinical and Experimental } \\
\text { Medicine } \\
\text { Vandooren, Jennifer; KULeuven, Department Microbiology \& Immunology } \\
\text { Lemmens, Bart; KULeuven, Department of Imaging \& Pathology } \\
\text { Van Lommel, Leentje; KULeuven, Department of Cellular and Molecular } \\
\text { Medicine } \\
\text { Breynaert, Christine; KULeuven, Department of Clinical and Experimental } \\
\text { Medicine } \\
\text { Van der Goten, Jan; KULeuven, Department of Clinical and Experimental } \\
\text { Medicine } \\
\text { Staelens, Dominiek; KULeuven, Department of Clinical and Experimental } \\
\text { Medicine } \\
\text { Billiet, Thomas; KULeuven, Department of Clinical and Experimental } \\
\text { Medicine } \\
\text { de Hertogh, Gert; KULeuven, Department of Imaging \& Pathology } \\
\text { Ferrante, Marc; KULeuven, Department of Clinical and Experimental } \\
\text { Medicine } \\
\text { Van Assche, Gert; KULeuven, Department of Clinical and Experimental } \\
\text { Medicine } \\
\text { Vermeire, Severine; KULeuven, Department of Clinical and Experimental } \\
\text { Medicine } \\
\text { Opdenakker, Ghislain; KULeuven, Department Microbiology \& Immunology } \\
\text { Schuit, Frans; KULeuven, Department of Clinical and Experimental } \\
\text { Medicine } \\
\text { Rutgeerts, Paul; KULeuven, Department of Clinical and Experimental } \\
\text { Medicine } \\
\text { Arijs, Ingrid; University Hospital Gasthuisberg, Leuven, Department of } \\
\text { Gastroenterology }\end{array}$ \\
\hline Keywords: & $\begin{array}{l}\text { inflammatory bowel disease, tissue remodeling genes, mucosal expression, } \\
\text { infliximab }\end{array}$ \\
\hline
\end{tabular}




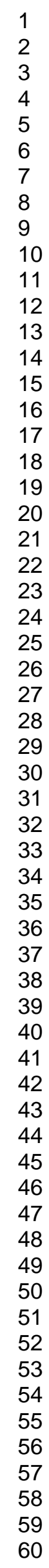

SCHOLARONE $^{\text {'m }}$

Manuscripts 
Infliximab restores the dysfunctional matrix remodeling protein and growth factor gene expression in patients with inflammatory bowel disease

Magali de Bruyn, $\mathrm{MS}^{1,2}$; Kathleen Machiels, $\mathrm{MS}^{1}$; Jennifer Vandooren, $\mathrm{MS}^{2}$; Bart Lemmens, $\mathrm{MS}^{4}$; Leentje Van Lommel, $\mathrm{MS}^{3}$; Christine Breynaert, MD ; Jan Van der Goten, Ing ${ }^{1}$; Dominiek Staelens, MS ${ }^{1}$; Thomas Billiet, MD'; Gert De Hertogh, MD, $\mathrm{PhD}^{4}$; Marc Ferrante, $\mathrm{MD}, \mathrm{PhD}^{1}$; Gert Van Assche, $\mathrm{MD}, \mathrm{PhD}^{1}$; Séverine Vermeire, MD, $\mathrm{PhD}^{1}$; Ghislain Opdenakker, $\mathrm{MD}, \mathrm{PhD}^{2}$; Frans Schuit, $\mathrm{MD}, \mathrm{PhD}^{3}$; Paul Rutgeerts, $\mathrm{MD}, \mathrm{PhD}^{1,5}$ and Ingrid Arijs, $\mathrm{PhD}^{1,3}$

${ }^{1}$ Translational Research Center for Gastrointestinal Disorders (TARGID), Department of Clinical and Experimental Medicine, KULeuven, Leuven, Belgium.

${ }^{2}$ Laboratory of Immunobiology (Rega Institute for Medical Research), Department of Microbiology and Immunology, KULeuven, Leuven, Belgium.

${ }^{3}$ Gene Expression Unit, Department of Cellular and Molecular Medicine, KULeuven, Leuven, Belgium.

${ }^{4}$ Translational Cell \& Tissue Research, Department of Imaging \& Pathology, KULeuven, Leuven, Belgium.

${ }^{5}$ Leuven Food Science and Nutrition Research Centre (LFoRCe), KULeuven, Leuven, Belgium.

\section{Correspondence:}

- Prof. Dr. Paul Rutgeerts, TARGID, KULeuven, University of Hospital Gasthuisberg, Herestraat 49, mailbox 7003, B-3000 Leuven, Belgium; phone +32-16-344225, fax +32-16-344419, email paul.rutgeerts@med.kuleuven.be 
- Dr. Ingrid Arijs, TARGID, KULeuven, Herestraat 49, O\&N1, mailbox 701, B3000 Leuven, Belgium; phone +32-16-330277, fax +32-16-345939, email ingrid.arijs@med.kuleuven.be

\title{
ACKNOWLEDGMENTS
}

Grant support: This work was supported by grants from the Fund for Scientific Research-Flanders (FWO-Flanders), Belgium (FWO project nr.G.0440.06 and nr.G.0479.10). IA is a postdoctoral fellow and SV is a clinical researcher of FWOFlanders. MdB and $\mathrm{CB}$ are supported by a grant of the Agency for Innovation by Science and Technology in Flanders (IWT).

\section{DISCLOSURES}

Paul Rutgeerts, Séverine Vermeire, Marc Ferrante, Gert Van Assche and Gert De Hertogh report following conflicts of interest: grant support, lecture fees and consulting fees from Centocor and Schering-Plough.

\begin{abstract}
Background: Matrix metalloproteinases (MMPs), MMP-inhibitors (TIMPs), ADAM(TS)s and growth factors are involved in inflammation and tissue damage and repair, all occurring in inflammatory bowel disease (IBD). We studied the impact of anti-inflammatory therapy with infliximab on mucosal expression of these tissue remodeling genes in IBD patients.
\end{abstract}

Methods: Mucosal gene expression of 23 MMPs, 4 TIMPs, 50 ADAM(TS)s and 158 growth factors was investigated in 61 IBD patients before and after first infliximab 
therapy and in 12 controls, with microarrays and quantitative RT-PCR. Protein localization, mucosal gelatinase levels and net gelatinolytic activity were investigated by immunohistochemistry, zymography analysis and gelatin degradation assay, respectively.

Results: In active IBD patients before infliximab vs. controls, gene expression of many MMPs, TIMPs, ADAM(TS)s and growth factors was upregulated, whereas colonic expression of MMP28 and TGFA, and ileal expression of ADAMDEC1 and $A G T$ were downregulated. After controlling inflammation with infliximab, most gene dysregulations observed at baseline were restored in responders. Increased ratio of MMP1/TIMP1 expression at baseline in active IBD was restored in responders with colonic mucosal healing. Immunohistochemistry for MMP1, MMP3, TIMP1 and REG1A showed higher protein levels in active IBD patients vs. inactive patients or controls. With zymography analysis and gelatin degradation assay higher gelatinase levels and net gelatinolytic activity were measured before infliximab and levels normalized after infliximab.

Conclusions: Our data suggest that suppression of inflammation results in arrest of epithelial damage and subsequent mucosal healing. Therefore, the therapeutic potential of agents targeting MMPs or growth factors as primary therapy seems rather complex.

Key Words: inflammatory bowel disease, infliximab, mucosal expression, tissue remodeling genes

\section{INTRODUCTION}


Crohn's disease (CD) and ulcerative colitis (UC) are chronic disabling inflammatory bowel diseases (IBD) with increasing prevalence throughout the whole world. IBD occurs mostly in young people and often leads to a greatly decreased quality of life, with (bloody) diarrhea and abdominal pain as major gastrointestinal symptoms. Despite extensive efforts, the exact pathogenesis of IBD remains unknown. However, it is believed that the chronic intestinal inflammation in IBD is the result of an inappropriate and ongoing activation of the mucosal immune system towards the (normal) luminal microbiota in genetically susceptible individuals. This activation of the mucosal immune system is most likely facilitated by defects in both the intestinal epithelial barrier function ("leaky mucosal barrier”) and the mucosal immune system ("loss of immune tolerance") (1).

Chronic intestinal inflammation leads to tissue damage and subsequent tissue repair, and all these events are accompanied by an increased turnover of the extracellular matrix $(E C M)$. Disturbance in the balance between the synthesis and breakdown of ECM components is involved in the pathological findings of IBD, leading to progressive tissue destruction (e.g. ulcers and fistulas) or excessive deposition of collagens (major component of ECM) resulting in fibrosis (2). Matrix metalloproteinases (MMPs) and their inhibitors and growth factors are important players in this tissue remodeling process. MMPs are a family with over 20 members of $\mathrm{Zn}^{2+}$-dependent endopeptidases that degrade most components of the ECM in inflammatory diseases. Their proteolytic activity is tightly controlled by endogenous inhibitors, including the tissue inhibitors of metalloproteinases (TIMPs) (3). Previous selective studies in IBD have shown that the balance between specific MMPs and TIMPs and their expression are dysregulated in IBD (4-6), but a general picture remains so far elusive. The MMPs share sequential and structural motifs with ADAMs 
(a disintegrin and metalloproteinase) and ADAMTSs (ADAMs with thrombospondin type 1 motif), which have both adhesive and proteolytic activities. Growth factors are involved in the modulation of intestinal inflammation and repair during IBD, having a critical role in cellular proliferation, differentiation and angiogenesis (7). They also promote wound healing by stimulating ECM synthesis, in part by modulating the balance between MMPs and TIMPs (8). Finally, an intrinsic network of interactions between inflammatory cytokines and growth factors with the balances of proteinases and inhibitors exists in acute and chronic inflammatory diseases, in which tumor necrosis factor (TNF) is a key regulator (9). These interactions not only include the induction of growth factors and proteases by upstream agonists, such as TNF, but also the activation, potentiation and degradation of growth factors and proteinases by extracellular proteases (3;10). Infliximab (Remicade; Centocor, Inc., Malvern, PA, USA), a chimeric monoclonal antibody to tumor necrosis factor-alpha (TNF- $\alpha$ ), has become the mainstay of therapy in refractory IBD (11). Infliximab dramatically improves the quality of life in IBD patients. Besides inducing and maintaining remission in refractory IBD patients, treatment with infliximab leads to new treatment goals such as intestinal mucosal healing and a reduction in hospitalizations and surgeries on the long-term. The intestinal mucosa of IBD patients is composed of different and changing cell types. The interactions between the immune cell populations and the non-immune cell types, including epithelial, mesenchymal, and microvascular endothelial cells, are important in the pathogenesis of IBD. Gene expression microarray profiling of the intestinal mucosa will represent an average of these different cell types, and gene expression by some cell populations (e.g. epithelial cells) may be decreased to the total mRNA pool, reflecting mucosal trafficking of inflammatory cell types in $\operatorname{IBD}(12)$. 
The study of gene expression in patients with IBD who achieved mucosal healing under infliximab in comparison with the gene expression before treatment allows us to obtain insights into the importance of the different mediators of inflammation, tissue degradation and tissue repair. Therefore, we investigated the intestinal mucosal gene expression of MMPs, TIMPs, ADAM(TS)s and growth factors in patients with active IBD, as well as the impact of anti-inflammatory therapy with infliximab on the mucosal expression of these genes, with the use of gene expression microarray technology. Validation of specific microarray data for selected genes was performed by quantitative real-time reverse-transcription PCR (qRT-PCR). In addition, immunohistochemistry was performed to evaluate protein levels and localization of MMP1, MMP3, TIMP1 and REG1A in active, inactive and control colonic and ileal mucosa. Zymography analysis was performed to investigate gelatinase levels before and after treatment with infliximab. Finally, a gelatin degradation assay was used to evaluate net gelatinolytic activity in the mucosal biopsies.

\section{MATERIALS and METHODS}

\section{MMPs, TIMPs, ADAM(TS)s and growth factors}

The gene expression of 23 MMPs, 4 TIMPs and 50 ADAM(TS)s and the expression of 158 genes encoding peptides/proteins with growth factor activity (see Supplementary table 1 for a detailed list of the genes) were investigated in intestinal mucosal biopsies obtained from normal controls and from IBD patients before and after their first infliximab treatment, using gene expression microarray technology.

\section{Patients and biopsy specimens}


This was a prospective observational cohort study (ClinicalTrials.gov number, NCT00639821). Sixty-one patients with active IBD, including 24 UC, 19 Crohn's colitis (CDc) and 18 Crohn's ileitis (CDi), refractory to corticosteroids and/or immunosuppression were studied. In table 1 the baseline characteristics of the patients and controls are shown.

A control group with normal mucosa of 12 individuals [6 colon and 6 ileum] who underwent endoscopy for screening for polyps was also included. The patients underwent endoscopy with biopsies from diseased bowel (colon for UC and CDC and ileum for $\mathrm{CDi}$ ) within a week prior to the first intravenous infliximab infusion of 5 $\mathrm{mg} / \mathrm{kg}$ body weight. The patients underwent a second endoscopy with biopsies 4 weeks after the first infliximab infusion in case of a single infusion and at 6 weeks if they received a loading dose of infliximab at weeks 0,2 and 6 . The biopsies were taken at sites of active inflammation but at a distance of ulcerations. In the case of healing at control endoscopy, the biopsies were obtained in the areas where lesions were present before therapy. The endoscopist was not blinded to treatment. Half of the biopsies were immediately snap-frozen in liquid nitrogen and stored at $-80^{\circ} \mathrm{C}$ until RNA isolation, except for the biopsies from $1 \mathrm{CDc}$ patient after infliximab treatment because of poor technical quality. The rest of the biopsies were fixed in Carnoy's fixative for up to 5 hours and then dehydrated, cleared and paraffin-embedded. Haematoxylin-eosin stained slides from the paraffin blocks of each patient were used to score the chronic intestinal inflammation, using a previously reported histological scoring system for UC (12) and for CD (13).

The response to infliximab therapy was assessed at the time of the second endoscopy, based on endoscopic and histologic findings. In the colon, the response was defined as a complete endoscopic mucosal healing (absence of ulcers) with a 
decrease of at least 3 points on the histological score for CDc (13) and as a decrease to a Mayo endoscopic subscore of 0 or 1 with a decrease to grade 0 or 1 on the histological score for UC $(12 ; 14)$. Patients who did not achieve this healing were considered non-responders although some of them showed endoscopic and/or histologic improvement. Of the 43 IBDc patients, we scored 20 responders (8 UC and $12 \mathrm{CDc}$ ) and 23 non-responders (16 UC and $7 \mathrm{CDc}$ ). When the same response criteria of CDc were used for $\mathrm{CDi}$, there was only one patient who showed in the ileum a complete endoscopic and histologic healing. Therefore, we used response criteria with lower stringency than complete healing in CDi. Patients with a clear improvement of the ulcerations and a decrease on the histological score (13) were defined as responders. Of the 18 CDi patients, 8 were (partial) responders and 10 were non-responders.

The characteristics of age, sex and smoking were compared between patients and controls. These comparisons were performed with the Mann-Whitney $U$-test for continuous variables and Fisher's exact test for categorical variables, using SPSS software (Chicago, IL) (Table 1). A p-value $\leq 0.01$ was considered significant.

\section{Whole-genome gene expression analysis}

As previously described (15), total RNA was extracted from the biopsy specimens and used to analyze the gene expression via Affymetrix Human Genome U133 Plus 2.0 Arrays (Affymetrix, Santa Clara, CA, USA), which are comprised of 54675 probe sets covering the whole genome. The microarray data have been submitted in MIAME (Minimum Information About a Microarray Experiment) format to the Gene Expression Omnibus database (series accession number GSE16879). 
Bioconductor tools (16) in R (version 2.7.2, http://www.r-project.org/) were used to analyze the Affymetrix raw data (.cel files). The robust multichip average method was performed on the Affymetrix raw data to obtain a log2 expression value for each probe set (17). Probe set annotations were obtained through the Affymetrix NetAffx website (http://www.affymetrix.com/analysis/index.affx) or the UCSC Genome Browser website (http://genome.ucsc.edu/) or the NCBI website (http://www.ncbi.nlm.nih.gov/). For comparative analysis, linear models for microarray data (LIMMA) (18) were performed for all probe sets present on the microarray to identify probe sets that are different between the groups, based on moderated $t$ statistics. For multiple testing correction, the false discovery rate (FDR) was estimated from $\mathrm{p}$-values derived from the moderated $t$-statistics using the method of Benjamini and Hochberg (19).

\section{qRT-PCR analysis}

To confirm the microarray data, qRT-PCR was performed for MMP1, MMP28, TIMP1, ADAM9, TFF1, TGFB1 and $\beta$-actin (as endogenous reference gene). cDNA was synthesized from $0.5 \mu \mathrm{g}$ of total RNA from the same samples as for microarray analysis, using the RevertAid $\mathrm{H}$ Minus First Strand cDNA synthesis kit (Fermentas, St. Leon-Rot, Germany), following the manufacturer's protocol. Primers and duallabelled probes were designed with OligoAnalyzer software (http://eu.idtdna.com/analyzer/applications/oligoanalyzer/default.aspx) and synthesized by Sigma-Aldrich (Bornem, Belgium) (Supplementary table 2). Multiplex real-time PCR was performed in a final reaction volume of $25 \mu \mathrm{l}$ on a RotorGene 3000 instrument (Corbett Research, Mortlake, Australia), using QuantiTect Multiplex PCR NoROX Kit (Qiagen, Venlo, NL), according to the manufacturer's 
instructions. Cycle threshold values were determined by Rotor-Gene 6.0.16 software. All samples were amplified in duplicate reactions. The relative expression of target mRNA levels were calculated as a ratio relative to $\beta$-actin reference mRNA (20). The results were analyzed with SPSS software, using Mann-Whitney U-test for unpaired samples and Wilcoxon signed-rank test for paired samples. A p-value $\leq 0.01$ was considered significant.

\section{Protein expression by immunohistochemistry}

To localize MMP1, MMP3, TIMP1 and REG1A in the intestinal mucosa, immunohistochemistry was performed on $5 \mu \mathrm{m}$-thick sections that were cut from paraffin blocks of formalin-fixed endoscopic biopsies from IBD patients and control individuals. After drying, deparaffinization and rehydration, epitope retrieval was performed at low $\mathrm{pH}$ for MMP1 and TIMP1, and at high $\mathrm{pH}$ for MMP3 and REG1A (Dako PT Link machine, Dako Belgium NV, Heverlee, Belgium). Sections were then washed 3 times 5 min (Envision Flex wash buffer, Dako) and Envision Flex Peroxidase-Blocking Reagent (Dako) was applied for $10 \mathrm{~min}$ at room temperature. After a second wash step, sections were incubated with an anti-human MMP1 rabbit polyclonal antibody (Bio-Rad AbD Serotec $\mathrm{GmbH}$, Düsseldorf, Germany; dilution 1/100), or with an anti-human MMP3 rabbit polyclonal antibody (Sigma-Aldrich, dilution 1/200), or with anti-human TIMP1 mouse monoclonal antibody (clone 102D1; Millipore, Overijse, Belgium; dilution 1/75), or with anti-human REG1A rabbit polyclonal antibody (Sigma-Aldrich, dilution 1/300) for $30 \mathrm{~min}$ at room temperature. Following a third wash step, bound primary antibody was visualized by incubating the slides for 30 min with Envision Flex/HRP (Dako) and application of the Envision $\mathrm{DAB}+$ Chromogen (Dako) for $10 \mathrm{~min}$ at room temperature. After rinsing, the slides 
were counterstained with haematoxylin, dehydrated, cleared and mounted. All the stains were evaluated by an experienced pathologist (GDH). Aside previous uses of the indicated antibodies, immunohistochemistry controls included omission of primary antibody and always yielded the expected negative signals.

\section{Zymography analysis}

Snap-frozen mucosal biopsies from a subset of active CDi patients $(n=3)$ and IBDC patients $(n=3)$ before and after treatment with infliximab, as well as control samples (3 ileum, 2 colon) were investigated with gelatin zymography analysis as described previously (21). Briefly, the weight of the biopsies was determined and $500 \mu$ of lysis buffer was added (50 mM Tris, $0.5 \mathrm{M} \mathrm{NaCl}, 10 \mathrm{mM} \mathrm{CaCl} 2,0.5 \%$ Triton-X 100, complete EDTA-free protease inhibitors (1 tablet/10 ml (Hoffmann-La Roche, Basel, Switzerland) $(\mathrm{pH} 7.5))$. The tissue was then homogenized with the Precellys 24 system (Bertin Technologies, Montigny-le-Bretonneux, France) and centrifuged 15 min at $20800 \mathrm{~g}$ at $4^{\circ} \mathrm{C}$. The supernatants, of which the volume was normalized to the starting weight of the biopsies, was then pre-purified using gelatin-Sepharose beads (GE healthcare, Buckinghamshire, United Kingdom) and mini-spin columns (Bio-Rad Laboratories, Hercules, CA, USA) (22). The bound gelatinases were eluted from the column with $20 \mu \mathrm{l}$ Tris/glycine/SDS non-reducing loading buffer (Invitrogen, Carlsbad, CA, USA) and the pre-purified samples were then separated in $7.5 \%$ acrylamide gels copolymerized with $1 \mathrm{mg} / \mathrm{ml}$ porcine gelatin (Sigma-Aldrich, St. Louis, MO, USA). The gels were then washed with 2.5\% Triton X-100 (Sigma-Aldrich, St. Louis, MO, USA) for $40 \mathrm{~min}$ and incubated overnight at $37^{\circ} \mathrm{C}$ in $50 \mathrm{mM}$ Tris- $\mathrm{HCl}(\mathrm{pH}$ 7.5) supplemented with $10 \mathrm{mM} \mathrm{CaCl}_{2}$ (Sigma-Aldrich, St. Louis, MO, USA). The gels were stained with $0.25 \%$ Coomassie Brilliant Blue-R (Sigma-Aldrich, St. Louis, MO, USA) 
and scanned using standard settings. Band densities were analyzed with Image $\mathrm{J}$ 1.48 software (NIH Windows version) and the obtained densities of different gelatinase forms were plotted as a ratio versus proMMP2 levels.

\section{Gelatin degradation assay}

The gelatin degradation assay was performed on snap-frozen mucosal biopsies from a subset of active CDi patients $(n=3)$ and IBDc patients $(n=3)$ before and after treatment with infliximab, as well as control samples (3 ileum, 3 colon). First, proteins were extracted from the biopsy samples in $500 \mu$ l assay buffer $(150 \mathrm{mM} \mathrm{NaCl}, 50$ $\mathrm{mM}$ Tris, $5 \mathrm{mM} \mathrm{CaCl}_{2}, 0.05 \%$ Tween20). Next, the net gelatinolytic activity was measured with the use of a previously described gelatin degradation assay (23). Briefly, the samples were added (duplicates) to a 96-well plate (chimney, black, clear bottom, Greiner Bio-one, Frickenhausen, Germany) and $\mathrm{DQ}^{\mathrm{TM}}$-gelatin (Invitrogen, Carlsbad, CA, USA) was added to a final concentration of $2.5 \mu \mathrm{g} / \mathrm{ml}$. Immediately thereafter, the plate was placed in a fluorescence reader (FL600 Microplate fluorescence reader, Biotek, Highland Park, IL, USA) and fluorescence was measured every 10 min for $4 \mathrm{~h}$ at $37^{\circ} \mathrm{C}$.

\section{ETHICAL CONSIDERATIONS}

The study was carried out at the University Hospital Gasthuisberg in Leuven (ClinicalTrials.gov number, NCT00639821). Written informed consent was obtained from all individuals and the study was approved by the University Hospital Ethics Committee.

\section{RESULTS}




\section{Gene expression of tissue remodeling genes in IBD intestinal mucosa before and after first infliximab therapy}

The intestinal mucosal gene expression microarray profiles were compared between normal controls, patients pre- and post-infliximab therapy in UC, CDc, IBD colitis (IBDc; UC and CDc together) and CDi.

In the current microarray study, we studied the intestinal mucosal gene expression of 23 MMPs, 4 TIMPs, 50 ADAM(TS)s and 158 growth factors. On the Affymetrix Human Genome U133 Plus 2.0 Array, the 23 MMPs were represented by 45 probe sets, the 4 TIMPs by 9 probe sets, the 50 ADAM(TS)s by 112 probe sets and the growth factors by 318 probe sets (Supplementary table 1). We only focussed on those probe sets that were expressed in the gut. Therefore, the probe sets with low overall intensity were excluded and only the probe sets with an intensity more than $\log 2(50)$ in at least $10 \%$ of the samples $(n=133)$ were included. This filter criterion leaves 22 probe sets representing 13 MMPs, 8 probe sets representing 3 TIMPs, 18 probe sets representing 14 ADAM(TS)s and 100 probe sets representing 69 growth factors for further analysis (Supplementary table 1). The results for these filtered probe sets were selected from all performed comparative analyses (Supplementary table 3 ). In the comparative analyses, the filtered probe sets with $>2$-fold change and FDR $<0.05$ were considered biologically significant. Additionally, we found that the characteristic age was significantly different between IBD patients and controls (Table 1). To investigate if age has an impact on the expression of the tissue remodeling genes in IBD and controls, LIMMA analysis between IBD patients (before therapy) and controls was performed with age as confounding factor. The results of the comparative analysis with age as confounder were similar as for the analysis without age as confounding factor. So there was no impact of the age on the 
expression of the tissue remodeling genes between IBD patients and controls (Supplementary table 4). Moreover, no evidence was found for age-related differential gene expression in active IBD patients and controls (results not shown).

\section{Expression of MMPs, TIMPs and ADAM(TS)s}

First, we studied whether differences existed in gene expression of MMPs, TIMPs and $A D A M(T S) s$ in active UC as compared with active CDc. We observed no significant gene expression differences at baseline (= pre-infliximab therapy) in inflamed colon between UC and CDc (Supplementary table 3). Second, we investigated the differential expression in MMP, TIMP and ADAM(TS) genes at baseline between active CDc and active CDi. Only MMP12 expression was more than 2-fold significantly downregulated at baseline in active CDi as compared to active CDc (Supplementary table 3).

Third, we investigated the differential gene expression of MMPs, TIMPs and ADAM(TS)s in inflamed mucosa of IBD patients and the effect of infliximab therapy on the expression of these genes (Table 2 and 3 ). In IBDc, the gene expression levels of MMP1-3, MMP7, MMP9-10, MMP12, MMP19, TIMP1-2, ADAM9, ADAM19, ADAM28, ADAMTS1 and ADAMTS9 were more than 2-fold significantly increased, whereas only MMP28 gene expression was more than 2-fold significantly decreased at baseline in inflamed colon as compared to control colons. Most of the MMP and TIMP genes upregulated at baseline in active IBDc decreased more than 2-fold significantly after infliximab therapy in IBDc responders when compared to baseline, and MMP28 expression was more than 2-fold significantly increased (Table 2). In contrast, no significant changes of these genes were observed in IBDc nonresponders after therapy when compared to their baseline samples (Supplementary 
table 3). These findings validate reciprocally the microarray data versus the endoscopic/histological findings. None of the MMP, TIMP and ADAM(TS) genes remained dysregulated after infliximab therapy in IBDc responders as compared to control colons, whereas most of the dysregulated genes at baseline remained dysregulated after therapy in IBDc non-responders when compared to control colons (Table 2).

Furthermore, we observed that in active IBDc before therapy versus control colons the fold change of the significant MMP1 (85.57x), MMP3 (67.93x), MMP10 (16.98x) and MMP12 (28.72x) was much higher than the fold change of the significant TIMPs [TIMP1 (11.51x) and TIMP2 (2.16x) (Table 2). In IBDc responders after therapy versus control colons, the fold change for both MMPs and TIMPs was around 1 (Table 2).

In CDi, the gene expression levels of MMP1, MMP3, MMP7, MMP10 and TIMP1 were more than 2-fold significantly upregulated, whereas only $A D A M D E C 1$ gene expression was more than 2-fold significantly downregulated at baseline in inflamed ileum as compared to control ileums. After infliximab therapy, no genes remained dysregulated in CDi responders as compared to control ileums, whereas the expression levels of MMP1, MMP3 and TIMP1 remained more than 2-fold significantly upregulated in CDi non-responders when compared to control ileums (Table 3).

Moreover, the ratio between the fold change of MMP1 and TIMP1, MMP3 and TIMP1, and MMP10 and TIMP1 in active CDi before therapy vs. control ileums was also increased (Table 3) as in IBDc before therapy.

Next, we studied the correlation of the expression of the MMP, TIMP and ADAM(TS) genes that were dysregulated at baseline in active disease with the gene expression 
of granulocyte markers (S100A8, S100A9 and S100A12), an inflammatory marker (interleukin 8 (IL8)) and an epithelial marker (villin 1 (VIL1)). The correlations were analyzed with the Spearman's Rank Correlation test using the microarray log2 mRNA expression values, and a p-value $\leq 0.01$ was considered significant (Supplementary table 5). The colon $(n=91)$ and ileum $(n=42)$ samples were analysed separately. A highly positive significant correlation was found for the mRNA levels for all upregulated MMPs, TIMPs and ADAM(TS)s with the mRNA levels of S100A8, S100A9, S100A12 and IL8 for both colon and ileum samples. A negative significant correlation was seen between the colonic mRNA levels of the downregulated MMP28 and VIL1, and between the ileal mRNA levels of the downregulated ADAMDEC1 and VIL1.

\section{Expression of growth factor genes}

Two rationales incited us to study growth factor gene expression levels in intestinal biopsies. First, many balances between MMPs and inhibitors are regulated by growth factors, and ADAM(TS)s have a prominent role in growth and development. Second, IBD results in epithelial tissue regenerative processes and healing processes involve growth regulating cytokines.

First, we studied the differential gene expression of growth factors at baseline in inflamed colon between active UC and active CDC, and we found no significant differences in gene expression of growth factors at baseline between active UC and active CDc (Supplementary table 3). Second, the differential gene expression of growth factors was studied at baseline between active CDc and active CDi. At baseline, the gene expression levels of FGF9, MACC1, MST1 and PDGFC were more than 2-fold significantly higher, and AREG, BMP2, CTGF and LEFTY1 gene 
expression levels were more than 2-fold significantly lower in active CDi when compared to active CDc (Table 4).

Third, the gene expression of growth factors was studied in inflamed mucosa of active IBD patients and the impact of infliximab therapy on the expression of these genes was evaluated (Tables 5 and 6). In IBDc, the colonic gene expression of $A G T$, ANGPTL2, AREG, CECR1, CTGF, FGF7/KGFLP1/KGFLP2, GMFG, HBEGF, HDGFRP3, INHBA, JAG1, MANF, REG1A, TFF1-2, TGFB1 and TYMP was more than 2-fold significantly upregulated, whereas only TGFA gene expression was more than 2-fold significantly downregulated before infliximab therapy in inflamed colon as compared to control colons. The expression of many growth factor genes which were upregulated at baseline in inflamed IBD colon were no longer significantly upregulated after therapy in IBDc responders when compared to control colons. As an exception, we observed that the colonic expression levels of $A R E G$ and JAG1 remained more than 2-fold significantly higher in IBDc responders after infliximab therapy as compared to control levels in the colon (Table 5). In contrast, most of the growth factor dysregulations observed at baseline in inflamed IBDc colon remained dysregulated after infliximab therapy in IBDc non-responders (Table 5). Of notice, the gene expression level of REG1A was more than 70 times higher in IBDc when compared to control colons and after infliximab treatment the expression was restored in IBDc responders but not in IBDc non-responders.

In CDi, only TFF1 mRNA expression was more than 2-fold significantly increased at baseline in inflamed ileum when compared to control ileums. In contrast with inflamed CDc colon, AGT mRNA expression levels were more than 2-fold significantly decreased at baseline in inflamed CDi ileum versus control ileums. After infliximab therapy, only $A G T$ expression remained downregulated in CDi responders, and TFF1 
and $A G T$ expression remained significantly dysregulated in CDi non-responders as compared to control ileums (Table 6).

Finally, all upregulated growth factor genes at baseline in active IBD correlated positively with the granulocyte markers (S100A12, S100A8 and S100A9) and the inflammatory marker IL8, except for the colonic mRNA levels of AREG, HBEGF, JAG1 and the ileal $A G T$ mRNA levels. A strong positive significant correlation was found between the colonic mRNA levels of the downregulated TGFA and the epithelial marker VIL1, and no correlation was seen between the ileal mRNA levels of the downregulated AGT and VIL1 (Supplementary table 5).

\section{Validation of selected microarray data by qRT-PCR}

We were able to confirm with the use of qRT-PCR the gene expression microarray results for MMP1, MMP28, TIMP1, ADAM9, TFF1, TGFB1, the ratio MMP1/TIMP1 (Figures 1 and 2, and Supplementary table 6) between controls and IBD patients before and after treatment.

As compared to control colons, the gene expression levels of MMP1, TIMP1, ADAM9 and TGFB1 were all significantly increased, and only MMP28 was significantly decreased in the inflamed colon of active IBDc patients. None of these genes remained significantly dysregulated after therapy in IBDc responders vs. control colons, whereas in IBDc non-responders the gene expression of MMP1, TIMP1, ADAM9 and MMP28 remained significantly dysregulated after therapy when compared to control colons. Moreover, the ratio of MMP1/TIMP1 gene expression was significantly increased in active IBDc versus control colons, and this imbalance was restored after therapy in IBDc responders when compared to control colons. 
As compared to control ileums, the gene expression levels of MMP1, TIMP1, ADAM9, TFF1 and the ratio MMP1/TIMP1 were all significantly increased in the inflamed ileum of CDi patients. After infliximab therapy, none of these genes remained significantly dysregulated in CDi responders vs. control ileums, except for MMP1 gene expression which remained significantly upregulated after therapy in CDi responders vs. control ileums. This increased MMP1 gene expression after therapy in CDi responders (7.21 times increase) was also observed by microarray analysis but no significance was reached $(F D R=0.13)$ (Table 3 and Supplementary table 3 ).

\section{Protein expression of MMP1, MMP3, REG1A and TIMP1 in ileal and colonic biopsies}

Immunohistochemistry was performed to localize MMP1, MMP3, REG1A and TIMP1 in the intestinal mucosa of controls and IBD patients with active and inactive disease. In normal mucosa MMP1 was expressed in the cytoplasm of primitive cells at the base of the crypts (Figure $\mathbf{3 A}$ ), whereas active IBD mucosa showed an increased expression of MMP1 in immature and surface epithelium cells according to the regeneration of the epithelial layer (Figure 3A). Moreover, MMP1 expression was found in endothelial cells of active IBD patients nearby active inflammation areas. In normal mucosa, MMP3 was detected in mononuclear inflammatory cells (Figure 3B). In active IBD mucosa, there was an increased expression of MMP3 according to the increased amount of mononuclear inflammatory cells (Figure 3B). REG1A was expressed mainly in the Paneth cells at the base of the crypts in normal mucosa (Figure 3C), whereas an enhanced expression of REG1A was seen in immature and surface epithelium cells of active IBD patients (Figure 3C). TIMP1 expression was seen in enteroendocrine cells at the base of the crypts, but no clear differences could 
be found in TIMP1 expression levels between control, inactive or active mucosa (Figure 3D).

\section{Gelatinase levels and net gelatinolytic activities before and after treatment with infliximab}

Zymography analysis was performed to determine gelatinase (MMP9 and MMP2) levels in mucosal biopsies taken from 3 IBDc and $3 \mathrm{CDi}$ responder patients before and after infliximab, and 5 controls ( 3 ileum, 2 colon). In figure 4 and supplementary figure $\mathbf{1}$, a clear trend for higher gelatinase levels was seen before infliximab therapy when compared to levels after therapy or control levels. Interestingly, no NGAL-MMP9 or activated MMP9 levels were measured in control tissues. In addition, a gelatin degradation assay was performed to determine the net gelatinolytic activity present in the mucosal biopsies. Overall, a trend was seen for elevated gelatinolytic activity levels before infliximab treatment and a decrease to control activity levels after treatment (Figure 5). Moreover, two patients (1 CDi and 1 IBDc responder) had markedly high activity levels before infliximab.

\section{DISCUSSION}

In IBD a disturbed and high intestinal turnover is observed during the sequence of inflammation, tissue destruction and repair, resulting in tissue morphological changes (e.g. ulcers, fibrosis) $(2 ; 4 ; 7 ; 24 ; 25)$. MMPs, ADAM(TS)s, TIMPs and growth factors play a major role in this tissue remodeling process. Achievement of mucosal healing in IBD responders to infliximab treatment allowed us to identify, during the evolution of the healing process, the changes that occur with healing in mediators of mucosal damage and repair in IBD. 
In the present gene expression microarray study we investigated the intestinal mucosal expression of MMP, ADAM(TS), TIMP and growth factor genes in active IBD and the influence of thorough downregulation of inflammation by infliximab therapy on the mucosal expression of these genes. With the use of qRT-PCR we confirmed the microarray data of selected genes.

In this study, no significant differences in expression of these genes were found at baseline in inflamed colon between $\mathrm{CDC}$ and UC, whereas there was a large difference in gene expression before therapy between active CDc and active CDi, especially for the growth factors. Before infliximab therapy, our microarray study further showed that the gene expression of 8 MMPs (MMP1, 2, 3, 7, 9, 10, 12 \& 19), 3 TIMPs (TIMP1, 2 \& 3), 5 ADAM(TS)s (ADAM9, $19 \& 28$ and ADAMTS1 \& 9) and many growth factors was significantly upregulated, whereas only the expression of MMP28 and TGFA was significantly downregulated before therapy in inflamed colon in UC and/or CDc as compared to control colons. As earlier described (26), the most upregulated gene in IBDc inflamed colon is the cell proliferation gene REG1A (>50fold). Besides IBD, upregulated REG1A is also associated with type 1 diabetes, celiac disease and pancreatic cancer (27-29), and has been proposed to act as a mitogenic and/or an anti-apoptotic factor in the development of UC-associated neoplasia (30). Moreover, the analysis of protein levels and localization with immunohistochemistry demonstrated that REG1A was expressed by Paneth cells in normal conditions, whereas in active disease REG1A levels increased and the expression shifted towards all epithelial cells of the mucosal crypts. These data confirm previous studies, whereby REG1A gene and protein expression levels were studied in inflamed and control colonic mucosa(31;32). 
The strong significantly upregulated (> 10-fold) MMP1, 3, 7, 10 \& 12 in active IBD colon were previously listed as one of the top upregulated genes in IBD colon in a large scale microarray study using open-access IBD datasets (26). In CDi before therapy, the expression levels of 4 MMPs (MMP1, 3, $7 \& 10)$, TIMP1 and TFF1 were significantly increased, and ADAMDEC1 and AGT were significantly decreased vs. control ileums. Of notice, AGT expression levels were decreased in active CDi ileum and no correlation was seen with the epithelial marker VIL1, whereas it was increased in active IBDc colon and a positive correlation was found with the inflammatory marker IL8, suggesting that AGT may play a causative role in CDi ileum. In earlier studies it was shown that the renin-angiotensin system is involved in colonic inflammation and fibrosis associated with IBD (33), but not much is known about its involvement in ileal IBD. The dysregulated expression of nearly all mediators present at baseline normalized after infliximab therapy in responders, but not in non-responders. The expression of almost all upregulated genes at baseline in active disease correlated strongly with the granulocyte markers S100A8, S100A9 and S100A12, and the inflammatory marker IL8, whereas the expression of the downregulated genes at baseline in active IBD correlated well with the epithelial marker VIL1. Both findings suggest that these dysregulations in active IBD are a consequence of the severe inflammation and epithelial damage in the intestine. Only the expression of 3 growth factors (AREG, JAG1 in colon and $A G T$ in ileum) remained significantly dysregulated after infliximab therapy in responders vs. controls. Further, the balance between MMPs and TIMPs is crucial, since any imbalance can result in an abnormally increased ECM turnover and remodeling, which can promote disease progression. In our study, MMP1, 3, 10 \& 12 expression levels were increased to a much greater extent (17-86x) than those of TIMPs $(2-12 x)$ 
in active IBDc before therapy vs. control colons. This is suggestive for an increased net MMP activity in IBDc which might partly explain the tissue destruction in IBD. This is in accordance with previously published data (34). The imbalance of MMP/TIMP was restored in IBDc responders to infliximab who developed complete mucosal healing. The increased ratios of MMP1, 3 and 10 vs.TIMP1 was also seen before therapy in CDi inflamed ileum. Previous studies showed that infliximab treatment of IBD intestinal mucosal implants decreased the ratio between MMP1, 3 \& 9 and both TIMP1 \& 2 (35). A gelatin degradation assay was performed to determine the net gelatinolytic activity in a subset of IBDC $(n=3)$, CDi $(n=3)$ and control individuals $(n=6)$. These data suggested that higher net gelatinolytic activity was present in mucosal biopsies before infliximab and the activity decreased to control levels after infliximab. Zymography analysis performed in this study showed that gelatinase (MMP2 and MMP9) levels had a trend to decrease after infliximab. These data were expected, since previous studies have shown that MMP2 and MMP9 decreased in mucosal biopsies (36) and serum (37) following infliximab therapy in CD. Interestingly, $1 \mathrm{CDi}$ and $1 \mathrm{IBDC}$ responder patient had particularly high net gelatinolytic activity levels and these patients also had the highest gelatinase levels as measured by zymography analysis (CDiR1 w0 and UCR1 w0, see supplementary figure 1). In addition, these high mucosal gelatinolytric activities normalized to control levels after treatment of with infliximab. This highlights the advantage of using both zymography analysis and a gelatin degradation assay. The combination of the tests enables to give information on presence, in a semiquantitative manner, and activity of the gelatinases in a biological sample (21)). Immunohistochemistry analysis of the highest upregulated genes (MMP1, MMP3, TIMP1 and REG1A) confirmed the microarray data and showed higher protein 
expression levels in active disease. These data are in line with previous studies $(32 ; 34 ; 38)$.

Various conclusions emerge from our analyses: (i) in comparison with developmentally regulated $\mathrm{ADAM}(\mathrm{TS}) \mathrm{s}$, inflammation-associated MMPs are stronger induced in IBD tissue vs. controls; (ii) TIMP1 (major inhibitor of MMP9) is co-induced at similar levels in IBDc as its major proteinase; (iii) many growth factors are switched on in active IBD tissue biopsies, suggesting regenerative processes; (iv) infliximab restores many of the dysfunctional expressions which underlines the role of TNF as an important switch for MMP and growth factor expression; and (v) the excellent correlation between clinical (endoscopic and histologic) differences of responders and non-responders and alterations in gene expression profiling suggests that both cellular and molecular signatures can be practically used in future studies.

Furthermore, our group showed in a previous microarray study that prior to infliximab therapy the gene expression levels of MMP1, 2, 3, 9, 10, $13 \& 19$ were lower in UC and/or CDc responders when compared to UC/CDC non-responders to infliximab (15;39), suggesting that these MMP genes are predictive for non-response of infliximab in IBDc.

Our data suggest that the critical step in mucosal healing in IBD is control of inflammation, blockade of migration of leukocytes and elimination of the inflammatory cells from the tissue. Consequently, the MMPs and TIMPs decrease or normalize and the imbalance of MMP/TIMP is restored in IBD responders to infliximab. Growth factors are upregulated with active inflammation. With mucosal healing, we observe a decrease of most growth factor expression to normal levels, suggesting that there is no need for an excess of these mediators to maintain healing. Our studies, therefore, indicate that the biological targets in IBD are mainly the key inflammatory mediators 
and the inflammatory cells. Targeting MMPs, TIMPS, ADAM(TS)s and growth factors may be beneficial in specific patients not responding to anti-TNF therapy but it is unlikely to achieve the same dramatic effects as the approach of targeting upstream inflammatory molecules or cells.

\section{FIGURE LEGENDS}

Figure 1: qRT-PCR analysis of MMP1 (A), MMP28 (B), TIMP1 (C), ADAM9 (D), TFF1 (E) and TGFB1 (F) in intestinal mucosa from IBD patients before and after first infliximab treatment and controls. A line between 2 points represents the change in expression before and after treatment for one patient. The x-axis labels of subfigures 1A, 1B, 1C and 1D are similar as shown in subfigure 1E and 1F. CDi: Crohn's ileitis, IBDC: colonic inflammatory bowel disease, NR: infliximab non-responders, R: infliximab responders, *significant $p$-value $\leq 0.01$.

Figure 2: The ratio MMP1/TIMP1 in intestinal mucosa from IBD patients before and after first infliximab treatment and controls, using the qRT-PCR expression data of MMP1 and TIMP1. A line between 2 points represents the change in expression before and after treatment for one patient. CDi: Crohn's ileitis, IBDc: colonic inflammatory bowel disease, NR: infliximab non-responders, $R$ : infliximab responders, * significant $p$-value $\leq 0.01$

Figure 3: Mucosal tissues from active CDi patients, IBDc patients and controls were stained by immunohistochemistry to localize MMP1 (A), MMP3 (B), REG1A (C) and TIMP1 (D). Arrow heads in the lower panel D indicate TIMP1 expression in 
enteroendocrine cells. Images were taken at $4 X$ and $20 X$ magnification, scale bars are shown in the right lower corner.

Figure 4: Gelatin zymography analysis on mucosal biopsies from active CDi and IBDc responders before and after treatment with infliximab, and controls. Levels of MMP9 and MMP2 forms are represented as a ratio vs. proMMP2 levels. Mean values with standard deviation of the mean (SEM) are shown. IBDCR: IBD colitis responder to infliximab, CDiR: CD ileitis responder to infliximab.

Figure 5: Gelatin degradation assay on mucosal biopsies from active CDi and IBDc responders before and after treatment with infliximab, and controls. Gelatinolytic activity is represented by fluorescence units over time. Mean values with standard deviation of the mean (SEM) are shown. IBDcR: IBD colitis responder to infliximab, CDiR: CD ileitis responder to infliximab.

\section{REFERENCES}

(1) Xavier RJ, Podolsky DK. Unravelling the pathogenesis of inflammatory bowel disease. Nature 2007;448(7152):427-34.

(2) Kusugami K, Nobata K, Tsuzuki T et al. Mucosal expression of matrix metalloproteinases and their tissue inhibitors in ulcerative colitis patients. $J$ Gastroenterol 2003;38(4):412-3.

(3) Hu J, Van den Steen PE, Sang QX et al. Matrix metalloproteinase inhibitors as therapy for inflammatory and vascular diseases. Nat Rev Drug Discov $2007 ; 6(6): 480-98$. 
(4) Ravi A, Garg P, Sitaraman SV. Matrix metalloproteinases in inflammatory bowel disease: boon or a bane? Inflamm Bowel Dis 2007;13(1):97-107.

(5) Rath T, Roderfeld M, Halwe JM et al. Cellular sources of MMP-7, MMP-13 and MMP-28 in ulcerative colitis. Scand J Gastroenterol 2010;45(10):1186-96.

(6) Makitalo L, Kolho KL, Karikoski $\mathrm{R}$ et al. Expression profiles of matrix metalloproteinases and their inhibitors in colonic inflammation related to pediatric inflammatory bowel disease. Scand J Gastroenterol 2010;45(78):862-71.

(7) Beck PL, Podolsky DK. Growth factors in inflammatory bowel disease. Inflamm Bowel Dis 1999;5(1):44-60.

(8) Burke JP, Mulsow JJ, O'Keane C et al. Fibrogenesis in Crohn's disease. Am J Gastroenterol 2007;102(2):439-48.

(9) Opdenakker G, Van Damme J. Cytokine-regulated proteases in autoimmune diseases. Immunol Today 1994;15(3):103-7.

(10) Van den Steen PE, Dubois B, Nelissen I et al. Biochemistry and molecular biology of gelatinase B or matrix metalloproteinase-9 (MMP-9). Crit Rev Biochem Mol Biol 2002;37(6):375-536.

(11) Rutgeerts P, Vermeire S, Van Assche G. Biological therapies for inflammatory bowel diseases. Gastroenterology 2009;136(4):1182-97.

(12) Geboes K, Riddell R, Ost A et al. A reproducible grading scale for histological assessment of inflammation in ulcerative colitis. Gut 2000;47(3):404-9.

(13) D'Haens GR, Geboes K, Peeters M et al. Early lesions of recurrent Crohn's disease caused by infusion of intestinal contents in excluded ileum. Gastroenterology 1998;114(2):262-7. 
(14) Rutgeerts P, Sandborn WJ, Feagan BG et al. Infliximab for induction and maintenance therapy for ulcerative colitis. N Engl J Med 2005;353(23):246276.

(15) Arijs I, Li K, Toedter G et al. Mucosal gene signatures to predict response to infliximab in patients with ulcerative colitis. Gut 2009;58(12):1612-9.

(16) Gentleman RC, Carey VJ, Bates DM et al. Bioconductor: open software development for computational biology and bioinformatics. Genome Biol 2004;5(10):R80.

(17) Irizarry RA, Hobbs B, Collin F et al. Exploration, normalization, and summaries of high density oligonucleotide array probe level data. Biostatistics 2003;4(2):249-64.

(18) Smyth GK. Linear models and empirical bayes methods for assessing differential expression in microarray experiments. Stat Appl Genet Mol Biol 2004;3:Article3.

(19) Benjamini Y, Hochberg Y. Controlling the false discovery rate: a practical and powerful approach to multiple testing. Journal of the Royal Statistical Society $B$ 1995;85:289-300.

(20) Pfaffl MW. A new mathematical model for relative quantification in real-time RT-PCR. Nucleic Acids Res 2001;29(9):e45.

(21) Vandooren J, Geurts N, Martens E et al. Zymography methods for visualizing hydrolytic enzymes. Nat Methods 2013;10(3):211-20.

(22) Descamps FJ, Martens E, Opdenakker G. Analysis of gelatinases in complex biological fluids and tissue extracts. Lab Invest 2002;82(11):1607-8. 
(23) Vandooren J, Geurts N, Martens E et al. Gelatin degradation assay reveals MMP-9 inhibitors and function of O-glycosylated domain. World $\mathrm{J}$ Biol Chem 2011;2(1):14-24.

(24) Barahona-Garrido J, Hernandez-Calleros J, Garcia-Juarez I et al. Growth factors as treatment for inflammatory bowel disease: a concise review of the evidence toward their potential clinical utility. Saudi J Gastroenterol 2009;15(3):208-12.

(25) Stenson WF. Mechanisms of tissue protection and repair in inflammatory bowel disease. Curr Opin Gastroenterol 2001;17(4):313-7.

(26) Clark PM, Dawany N, Dampier W et al. Bioinformatics analysis reveals transcriptome and microRNA signatures and drug repositioning targets for IBD and other autoimmune diseases. Inflamm Bowel Dis 2012.

(27) Park JY, Kim SA, Chung JW et al. Proteomic analysis of pancreatic juice for the identification of biomarkers of pancreatic cancer. J Cancer Res Clin Oncol 2011;137(8):1229-38.

(28) Planas R, Pujol-Autonell I, Ruiz E et al. Regenerating gene lalpha is a biomarker for diagnosis and monitoring of celiac disease: a preliminary study. Trans/ Res 2011;158(3):140-5.

(29) Astorri E, Guglielmi C, Bombardieri M et al. Circulating Reg1alpha proteins and autoantibodies to Reg1alpha proteins as biomarkers of beta-cell regeneration and damage in type 1 diabetes. Horm Metab Res 2010;42(13):955-60.

(30) Sekikawa A, Fukui H, Fujii S et al. Possible role of REG lalpha protein in ulcerative colitis and colitic cancer. Gut 2005;54(10):1437-44. 
(31) Dieckgraefe BK, Crimmins DL, Landt V et al. Expression of the regenerating gene family in inflammatory bowel disease mucosa: Reg lalpha upregulation, processing, and antiapoptotic activity. J Investig Med 2002;50(6):421-34.

(32) Granlund A, Flatberg A, Ostvik $A E$ et al. Whole genome gene expression meta-analysis of inflammatory bowel disease colon mucosa demonstrates lack of major differences between Crohn's disease and ulcerative colitis. PLoS ONE 2013;8(2):e56818.

(33) Garg M, Angus PW, Burrell LM et al. Review article: the pathophysiological roles of the renin-angiotensin system in the gastrointestinal tract. Aliment Pharmacol Ther 2012;35(4):414-28.

(34) Meijer MJ, Mieremet-Ooms MA, van der Zon AM et al. Increased mucosal matrix metalloproteinase $-1,-2,-3$ and -9 activity in patients with inflammatory bowel disease and the relation with Crohn's disease phenotype. Dig Liver Dis 2007;39(8):733-9.

(35) Meijer MJ, Mieremet-Ooms MA, van Duijn W et al. Effect of the anti-tumor necrosis factor-alpha antibody infliximab on the ex vivo mucosal matrix metalloproteinase-proteolytic phenotype in inflammatory bowel disease. Inflamm Bowel Dis 2007;13(2):200-10.

(36) Geboes K, Rutgeerts P, Opdenakker G et al. Endoscopic and histologic evidence of persistent mucosal healing and correlation with clinical improvement following sustained infliximab treatment for Crohn's disease. Curr Med Res Opin 2005;21(11):1741-54.

(37) Gao Q, Meijer MJ, Schluter UG et al. Infliximab treatment influences the serological expression of matrix metalloproteinase (MMP)-2 and -9 in Crohn's disease. Inflamm Bowel Dis 2007;13(6):693-702. 
(38) von Lampe B, Barthel B, Coupland SE et al. Differential expression of matrix metalloproteinases and their tissue inhibitors in colon mucosa of patients with inflammatory bowel disease. Gut 2000;47(1):63-73.

(39) Arijs I, Quintens R, Van Lommel L et al. Predictive value of epithelial gene expression profiles for response to infliximab in Crohn's disease. Inflamm Bowel Dis 2010;16(12):2090-8. 

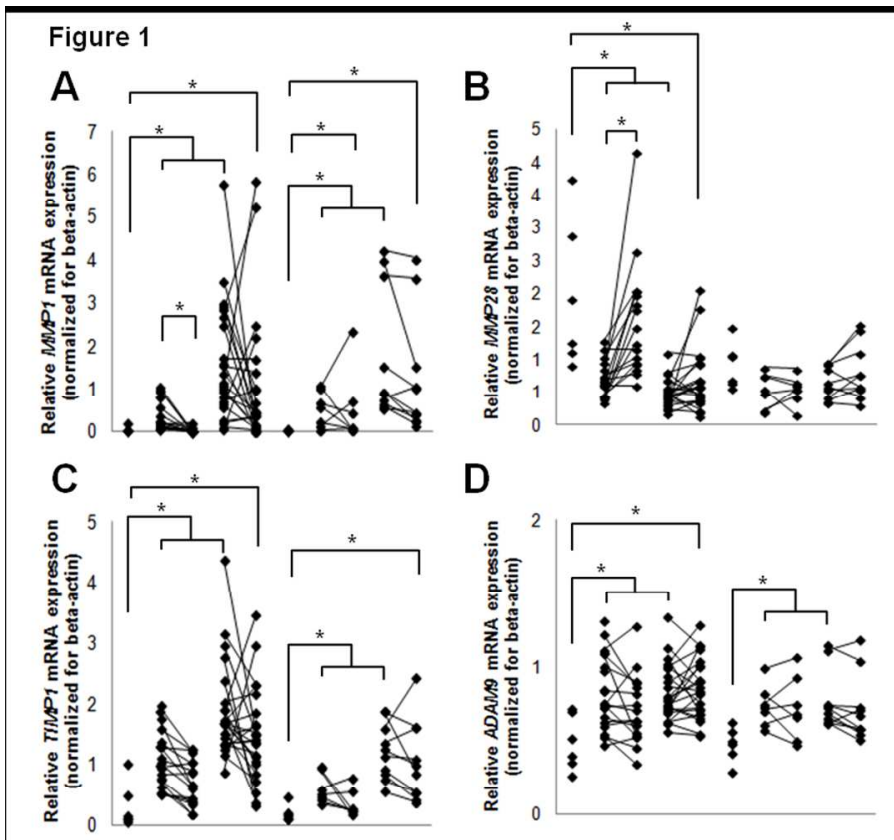

D

E

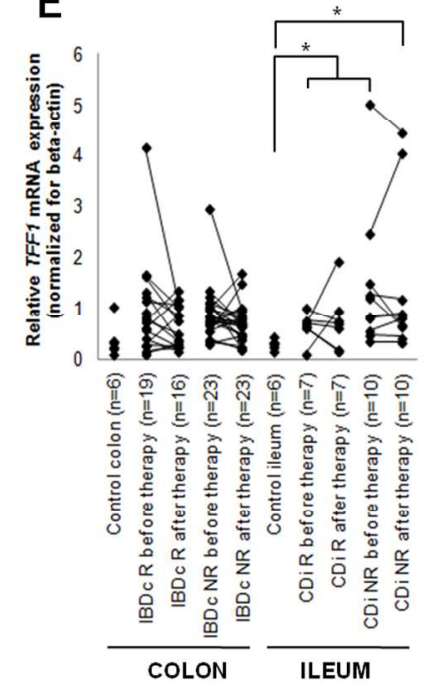

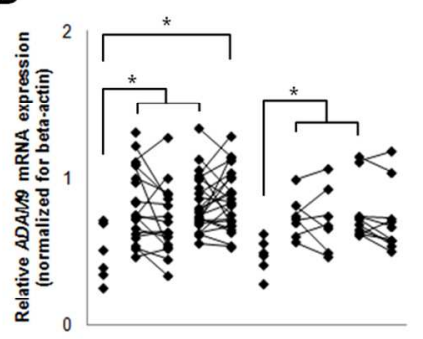

F

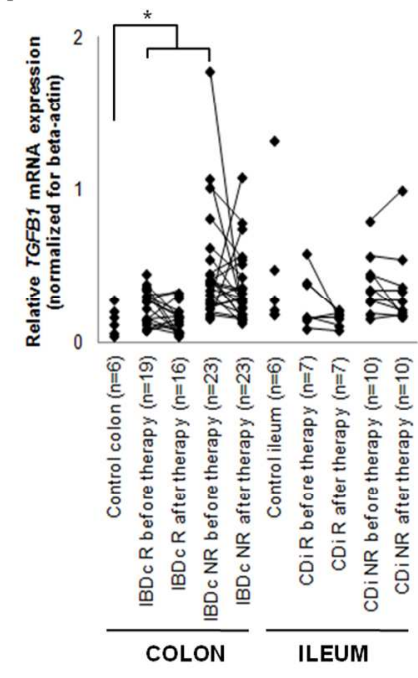

$245 \times 421 \mathrm{~mm}(300 \times 300 \mathrm{DPI})$ 
Figure 2

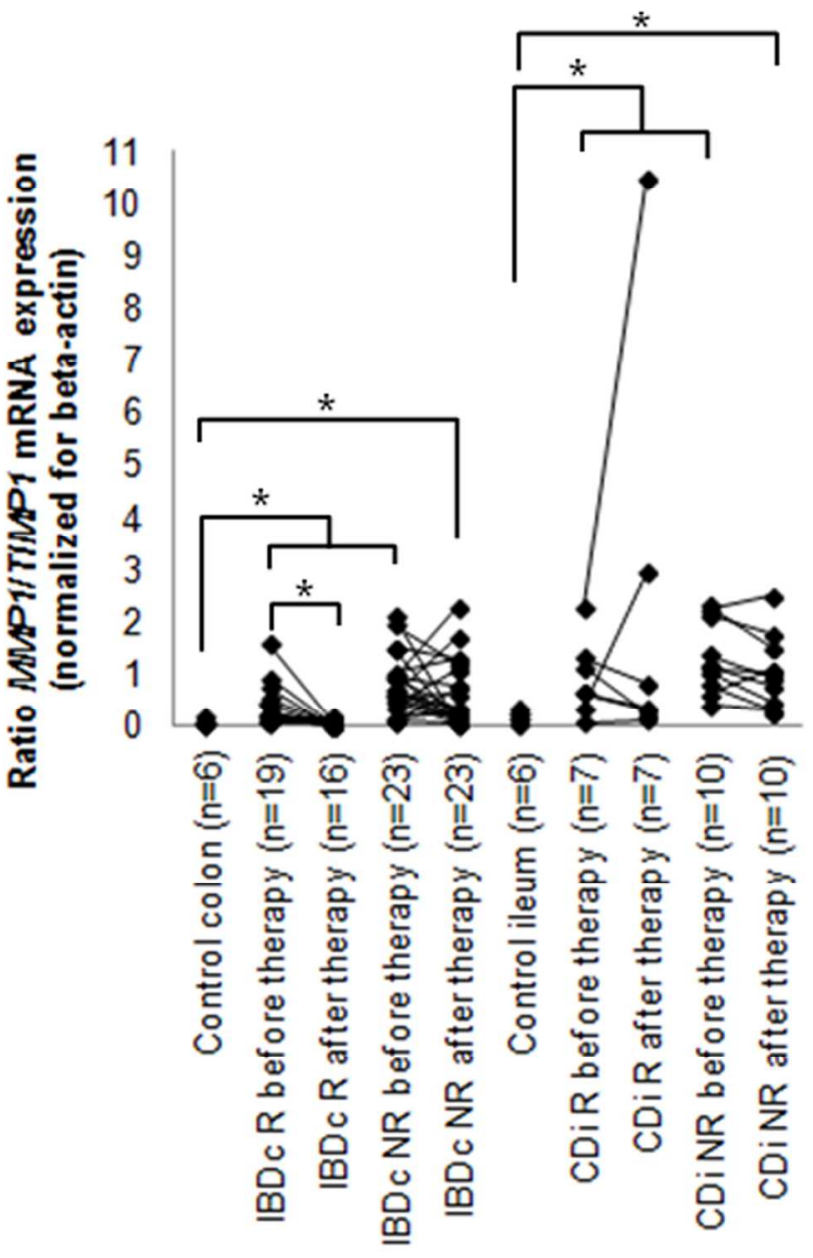

$78 \times 121 \mathrm{~mm}(300 \times 300 \mathrm{DPI})$ 


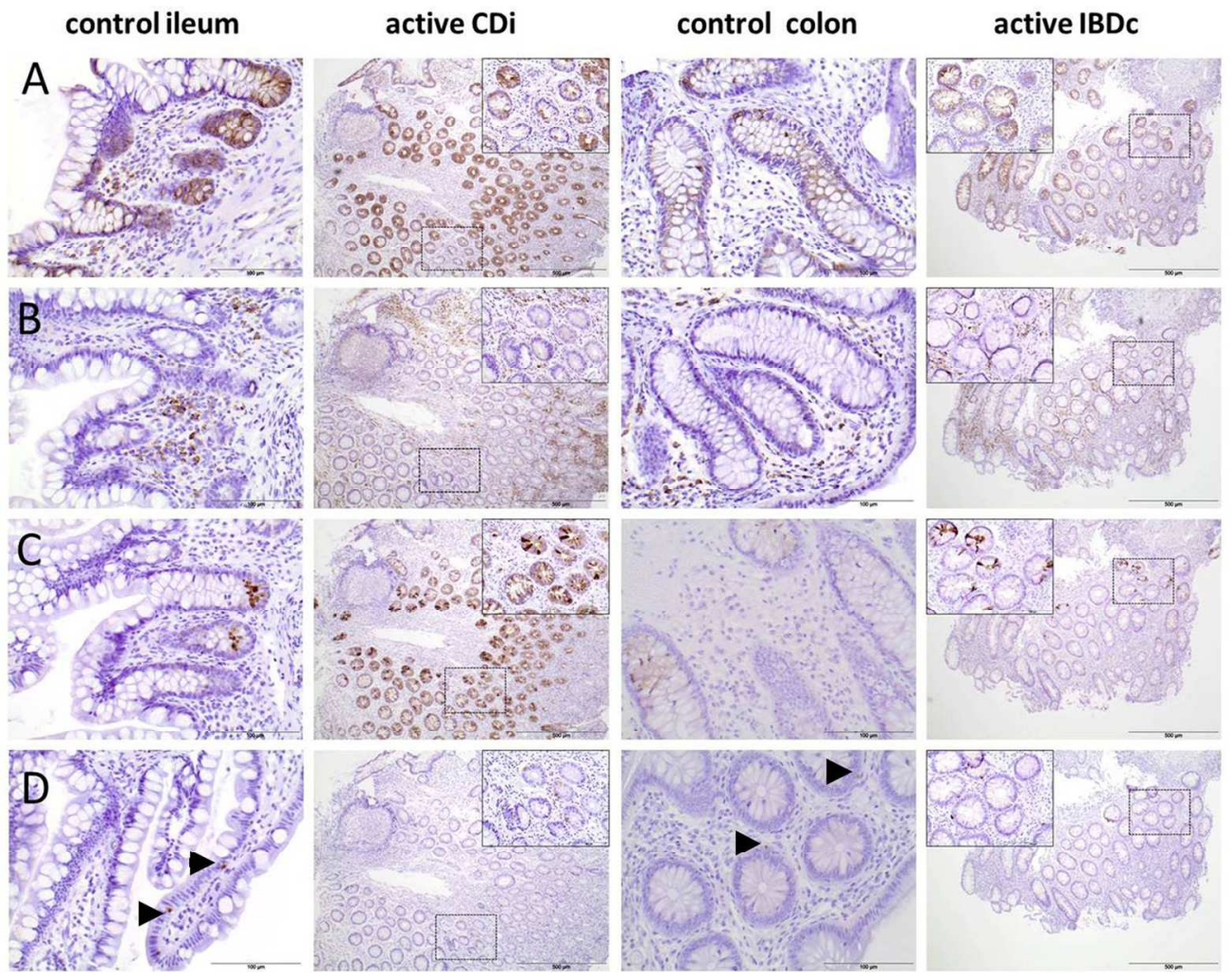

$190 \times 149 \mathrm{~mm}(300 \times 300$ DPI $)$ 
A

B
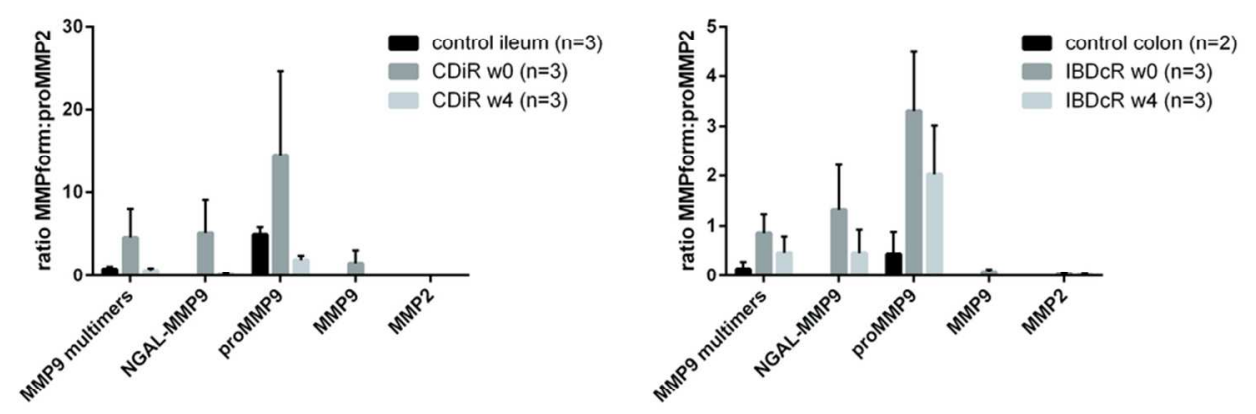

$87 \times 38 \mathrm{~mm}(300 \times 300$ DPI $)$ 
1

2

3

4

5

6

7

8

9

10

11

12

13

14

15

16

17

18

19

20

21

22

23

24

25

26

27

28

29

30

31

32

33

34

35

36

37

38

39

40

41

42

43

44

45

46

47

48

49

50

51

52

53

54

55

56

57

58

59

60
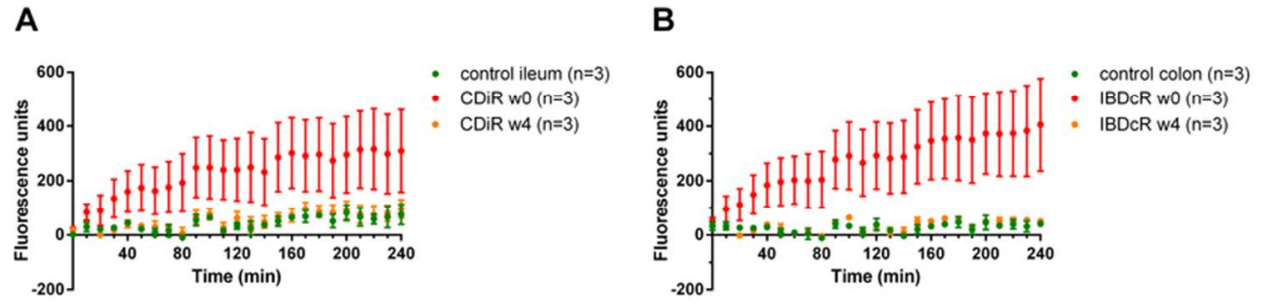

$73 \times 18 \mathrm{~mm}(300 \times 300$ DPI $)$ 
Table 1: Characteristics of IBD patients at first infliximab infusion and of control individuals.

\begin{tabular}{|c|c|c|c|c|c|c|}
\hline \multirow{2}{*}{ Baseline characteristics } & \multicolumn{3}{|c|}{ IBD (n:61) } & \multicolumn{2}{|c|}{ Controls $(n: 12)$} & \multirow{2}{*}{ P-value IBD vs. controls } \\
\hline & UC (n:24) & CDc (n:19) & CDi (n:18) & Controls colon (n:6) & Controls ileum $(n: 6)$ & \\
\hline Male/Female (\%) & $14 / 10(58.3 / 41.7)$ & $11 / 8(57.9 / 42.1)$ & $9 / 9(50 / 50)$ & $3 / 3(50 / 50)$ & $3 / 3(50 / 50)$ & 0.759 \\
\hline $\begin{array}{l}\text { Median }(\mathrm{IQR})^{*} \text { age (years) } \\
\text { Median (IQR) }{ }^{*} \text { duration of disease prior to first IFX }\end{array}$ & $41.4(31.9-50.9)$ & $31.8(23.7-47.5)$ & $46.4(34-55.3)$ & $73.07(71.31-76.67)$ & $51.8(34.11-57.33)$ & 0.002 \\
\hline \multicolumn{6}{|l|}{ Extent of disease } & NA \\
\hline UC Left-sided colitis (\%) & $7(29.2)$ & NA & NA & NA & NA & NA \\
\hline Pancolitis (\%) & $17(70.8)$ & NA & NA & NA & NA & NA \\
\hline CD lleocolon (\%) & NA & $5(26.3)$ & $9(50)$ & NA & NA & NA \\
\hline Ileum $(\%)$ & NA & $0(0)$ & $9(50)$ & NA & NA & NA \\
\hline Colon $(\%)$ & NA & $14(73.7)$ & $0(0)$ & NA & NA & NA \\
\hline Median $(\mathrm{IQR})^{*} \mathrm{C}$-reactive protein at first IFX (mg/L) & $4(1.8-19.1)$ & $10.2(4.3-35)$ & $7.4(2.3-10.9)$ & NA & NA & NA \\
\hline \multicolumn{7}{|l|}{ Concomitant medication at first IFX (\%) } \\
\hline 5-Aminosalicylates & $18(75)$ & $8(42.1)$ & $5(27.8)$ & NA & NA & NA \\
\hline Corticosteroids & $7(29.2)$ & $4(21.1)$ & $2(11.1)$ & NA & NA & NA \\
\hline Azathioprine/6-Mercaptopurine & $15(62.5)$ & $14(73.7)$ & $7(38.9)$ & NA & NA & NA \\
\hline Methotrexate & $0(0)$ & $0(0)$ & $0(0)$ & NA & NA & NA \\
\hline Corticosteroids + Immunosuppressants & $3(12.5)$ & $2(10.5)$ & $1(6)$ & NA & NA & NA \\
\hline Active smoking (\%) & $2(8.3)$ & $6(31.6)$ & $6(33.3)$ & $0(0)$ & $1(16.7)$ & 0.438 \\
\hline
\end{tabular}

*: datasets with skewed (non-normal) distributions, IQR: interquartile range, IFX: infliximab, NA: not applicable 
Table 2: Fold changes of the probe sets encoding MMP, TIMP and ADAM(TS) genes that were significantly different in the comparative analyses before therapy in IBDc inflamed colon versus control colons, and fold changes of these probe sets from the comparative analyses after infliximab therapy in IBDc. The abbreviations of the individual MMPs, TIMPs and ADAM(TS)s are explained in supplementary table 1.

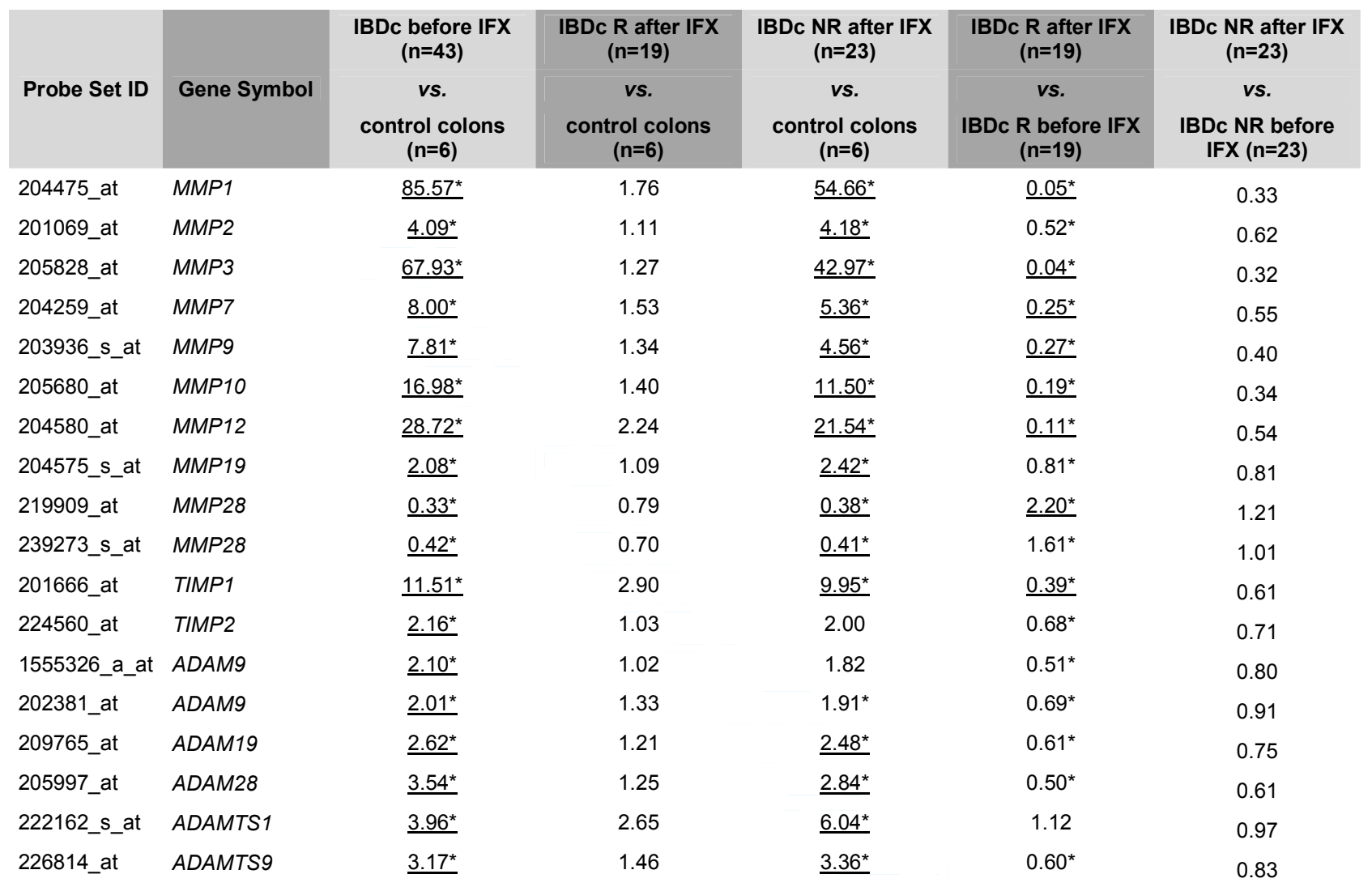

*: FDR < 0.05, underline: significant (> 2-fold change and FDR < 0.05), IFX: infliximab, R: responders, NR: non-responders 
Table 3: Fold changes of the probe sets encoding MMP, TIMP and ADAM(TS) genes that were significantly different in the comparative analyses before therapy in CDi inflamed ileum versus control ileums, and fold changes of these probe sets from the comparative analyses after infliximab therapy. The abbreviations of the individual MMPs, TIMPs and ADAM(TS)s are explained in supplementary table 1.

\begin{tabular}{|c|c|c|c|c|c|c|}
\hline Probe Set ID & $\begin{array}{l}\text { Gene } \\
\text { Symbol }\end{array}$ & $\begin{array}{l}\text { CDi before IFX (n:18) } \\
\qquad v s . \\
\text { control ileums ( } \mathrm{n}: 6)\end{array}$ & $\begin{array}{l}\text { CDi R after IFX ( } \mathrm{n}: 8) \\
\text { vs. } \\
\text { control ileums ( } \mathrm{n}: 6)\end{array}$ & $\begin{array}{l}\text { CDi NR after IFX } \\
\text { (n:10) } \\
\text { vs. } \\
\text { control ileums (n:6) }\end{array}$ & $\begin{array}{l}\text { CDi R after IFX (n:8) } \\
\text { vs. } \\
\text { CDi R before IFX } \\
(\mathrm{n}: 8)\end{array}$ & $\begin{array}{c}\text { CDi NR after IFX } \\
\text { (n:10) } \\
\text { vs. } \\
\text { CDi NR before IFX } \\
(\mathrm{n}: 10)\end{array}$ \\
\hline 204475_at & MMP1 & $\underline{22.04^{*}}$ & 7.21 & $\underline{21.12^{*}}$ & 0.63 & 0.57 \\
\hline 205828_at & $M M P 3$ & $\underline{47.58^{*}}$ & 2.82 & $\underline{24.92^{*}}$ & 0.15 & 0.25 \\
\hline 204259_at & MMP7 & $\underline{3.27^{*}}$ & 2.01 & 2.40 & 0.86 & 0.56 \\
\hline 205680_at & MMP10 & $\underline{6.69^{*}}$ & 1.82 & 3.74 & 0.40 & 0.41 \\
\hline 201666_at & TIMP1 & $\underline{5.71^{*}}$ & 1.79 & $\underline{5.57^{*}}$ & 0.48 & 0.70 \\
\hline 206134_at & $A D A M D E C 1$ & $\underline{0.42^{*}}$ & 0.35 & 0.32 & 0.79 & 0.80 \\
\hline
\end{tabular}

*: FDR < 0.05, underline: significant (> 2-fold change and FDR < 0.05), IFX: infliximab, R: responders, NR: non-responders 
Table 4: Fold changes of the probe sets encoding growth factor genes that were significant at 1 baseline between active $\mathrm{CDi}$ and active CDc. The abbreviations of the individual growth factors are explained in supplementary table 1.

\begin{tabular}{lll} 
Probe Set ID & Gene Symbol & $\begin{array}{c}\text { CDi before IFX (n:18) } \\
\text { vs. } \\
\text { CDc before IFX } \\
\text { (n:19) }\end{array}$ \\
\hline 205239_at & AREG & $\underline{0.23^{*}}$ \\
205289_at & BMP2 & $\underline{0.42^{*}}$ \\
205290_s_at & BMP2 & $\underline{0.42^{*}}$ \\
209101_at & CTGF & $\underline{0.42^{*}}$ \\
206404_at & FGF9 & $\underline{2.57^{*}}$ \\
206268_at & LEFTY1 & $\underline{0.06^{*}}$ \\
1559361_at & $M A C C 1$ & $\underline{2.17^{*}}$ \\
1566764_at & $M A C C 1$ & $\underline{3.31^{*}}$ \\
1566766_a_at & $M A C C 1$ & $\underline{2.30^{*}}$ \\
232151_at & $M A C C 1$ & $\underline{2.50^{*}}$ \\
205614_x_at & $M S T 1$ & $\underline{2.41^{*}}$ \\
216320_x_at & $M S T 1$ & $\underline{2.69^{*}}$ \\
218718_at & PDGFC & $\underline{2.03^{*}}$ \\
*: FDR < 0.05, underline: significant & $2-$ fold change \\
and FDR < 0.05), IFX: infliximab &
\end{tabular}


Table 5: The fold changes of the probe sets encoding growth factor genes that were significantly different in the comparative analyses before therapy in IBDc inflamed colon versus control colons, and the fold changes of these probe sets from the comparative analyses after infliximab therapy in IBDc. The abbreviations of the individual growth factors are explained in supplementary table 1.

\begin{tabular}{|c|c|c|c|c|c|c|}
\hline Probe Set ID & Gene Symbol & $\begin{array}{l}\text { IBDc before } \\
\text { IFX }(n=43) \\
\text { vs. } \\
\text { control colons } \\
(n=6)\end{array}$ & $\begin{array}{c}\text { IBDc R after } \\
\text { IFX }(n=19) \\
\text { vs. } \\
\text { control colons } \\
(n=6)\end{array}$ & $\begin{array}{c}\text { IBDc NR after } \\
\text { IFX }(n=23) \\
\text { vs. } \\
\text { control colons } \\
(n=6)\end{array}$ & $\begin{array}{l}\text { IBDc R after } \\
\text { IFX }(n=19) \\
\text { vs. } \\
\text { IBDc } R \text { before } \\
\text { IFX }(n=19)\end{array}$ & $\begin{array}{l}\text { IBDc NR after } \\
\text { IFX }(n=23) \\
\text { vs. } \\
\text { IBDc NR before } \\
\text { IFX }(n=23)\end{array}$ \\
\hline 202834_at & $A G T$ & $\underline{2.67^{*}}$ & 1.13 & $\underline{2.24^{*}}$ & $0.55^{\star}$ & 0.69 \\
\hline 213001_at & ANGPTL2 & $\underline{2.90^{*}}$ & 1.12 & $\underline{2.91^{*}}$ & $0.66^{*}$ & 0.65 \\
\hline 205239_at & AREG & $\underline{3.52^{*}}$ & $\underline{3.84^{*}}$ & $\underline{4.67^{*}}$ & 1.08 & 1.28 \\
\hline 219505_at & CECR1 & $\underline{3.37^{*}}$ & 1.33 & $\underline{3.11^{*}}$ & $0.56^{*}$ & 0.69 \\
\hline 209101_at & CTGF & $\underline{2.70^{*}}$ & 1.77 & $\underline{3.24^{*}}$ & 0.87 & 0.93 \\
\hline 1554741_s_at & $\begin{array}{c}\text { FGF7/ } \\
\text { KGFLP1/ } \\
\text { KGFLP2 }\end{array}$ & $\underline{3.94^{*}}$ & 1.60 & $\underline{4.78^{*}}$ & 0.78 & 0.71 \\
\hline 204220_at & GMFG & $\underline{3.35^{\star}}$ & 1.14 & $\underline{3.57^{*}}$ & $\underline{0.48^{*}}$ & 0.79 \\
\hline 203821_at & HBEGF & $\underline{2.34^{*}}$ & 3.00 & $\underline{3.56^{*}}$ & 1.28 & 1.43 \\
\hline 209524_at & HDGFRP3 & $\underline{2.15^{*}}$ & 1.44 & $\underline{2.45^{*}}$ & 0.98 & 0.82 \\
\hline 210511_s_at & INHBA & $\underline{3.19^{*}}$ & 0.77 & 3.62 & $0.51^{*}$ & 0.59 \\
\hline 231183_s_at & $J A G 1$ & $\underline{2.71^{*}}$ & $\underline{2.30^{*}}$ & $\underline{2.61^{*}}$ & 0.87 & 0.96 \\
\hline 202655_at & MANF & $\underline{2.33^{*}}$ & 1.49 & $\underline{2.38^{*}}$ & $0.67^{\star}$ & 0.97 \\
\hline 209752_at & REG1A & $\underline{71.30^{*}}$ & 3.36 & $\underline{31.27^{*}}$ & $\underline{0.05^{\star}}$ & 0.42 \\
\hline 205009_at & TFF1 & $\underline{2.94^{*}}$ & 1.60 & $\underline{2.52^{*}}$ & $0.61^{*}$ & 0.76 \\
\hline 214476_at & TFF2 & $\underline{2.62^{*}}$ & 1.30 & 1.96 & $0.58^{*}$ & 0.64 \\
\hline 205016_at & $T G F A$ & $\underline{0.45^{*}}$ & 0.57 & $\underline{0.42^{*}}$ & 1.31 & 0.91 \\
\hline 203085_s_at & TGFB1 & $\underline{2.42^{*}}$ & 1.10 & $\underline{2.48^{*}}$ & $0.72^{*}$ & 0.72 \\
\hline 204858_s_at & $T Y M P$ & $\underline{2.35^{*}}$ & 1.12 & $\underline{2.16^{*}}$ & $0.56^{*}$ & 0.79 \\
\hline
\end{tabular}

*: FDR < 0.05, underline: significant (> 2-fold change and FDR < 0.05), IFX: infliximab, R: responders, NR: non-responders 
Table 6: The fold changes of the probe sets encoding growth factor genes that were significantly different in the comparative analyses before therapy in CDi inflamed ileum versus control ileums, and the fold changes of these probe sets from the comparative analyses after infliximab therapy. The abbreviations of the individual growth factors are explained in supplementary table 1.

\begin{tabular}{|c|c|c|c|c|c|c|}
\hline \multirow[t]{2}{*}{ Probe Set ID } & \multirow{2}{*}{$\begin{array}{l}\text { Gene } \\
\text { Symbol }\end{array}$} & $\begin{array}{c}\text { CDi before IFX } \\
\text { (n:18) } \\
\text { vs. }\end{array}$ & $\begin{array}{c}\text { CDi R after IFX (n:8) } \\
\text { vs. }\end{array}$ & $\begin{array}{c}\text { CDi NR after IFX } \\
\text { (n:10) } \\
\text { vs. }\end{array}$ & $\begin{array}{c}\text { CDi R after IFX (n:8) } \\
\text { vs. }\end{array}$ & $\begin{array}{c}\text { CDi NR after IFX } \\
\text { (n:10) } \\
\text { vs. }\end{array}$ \\
\hline & & control ileums (n:6) & control ileums ( $\mathrm{n}: 6)$ & control ileums (n:6) & $\begin{array}{c}\text { CDi R before IFX } \\
(\mathbf{n}: 8)\end{array}$ & $\begin{array}{l}\text { CDi NR before IFX } \\
\text { (n:10) }\end{array}$ \\
\hline 202834_at & $A G T$ & $\underline{0.33^{*}}$ & $\underline{0.28^{*}}$ & $\underline{0.28^{*}}$ & 0.92 & 0.80 \\
\hline 205009_at & TFF1 & $\underline{2.94^{*}}$ & 2.03 & $\underline{3.17^{*}}$ & 0.95 & 0.83 \\
\hline
\end{tabular}

*: FDR < 0.05, underline: significant ( $>2$-fold change and FDR < 0.05), IFX: infliximab, R: responders, NR: non-responders 